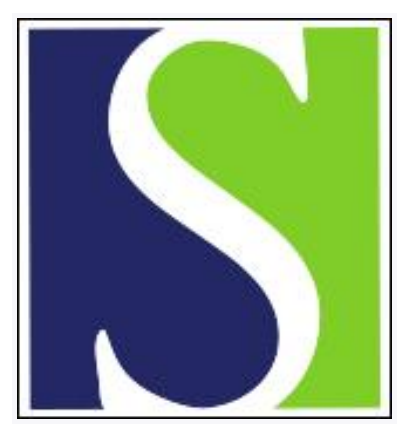

Scand J Work Environ Health 1996;22(2):133-138

https://doi.org/10.5271/sjweh.121

Issue date: Apr 1996

\title{
Circadian adjustment of men and women to night work
}

by Hakola T, Härmä MI, Laitinen JT

The following articles refer to this text: 2003;29(1):22-26;

2007;33(3):198-203; 2008;34(1):1-3; 2009;35(5):361-367;

2010;36(2):163-179

Key terms: laboratory study; rectal temperature; salivary cortisol; salivary melatonin; sex difference; sleep; subjective sleepiness

This article in PubMed: www.ncbi.nlm.nih.gov/pubmed/8738892

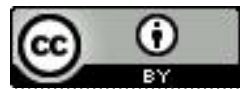




\title{
Circadian adjustment of men and women to night work
}

\author{
Tarja Hakola, MSc, ${ }^{1}$ Mikko I Härmä, MD, ${ }^{1}$ Jarmo T Laitinen, PhD ${ }^{2}$
}

\author{
Hakola T, Härmä MI, Laitinen JT. Circadian adjustment of men and women to night work. Scand J Work Environ \\ Health 1996;22:133-8.
}

\begin{abstract}
Objectives The aims of the present study were to define the adjustment of sleep-wakefulness and other circadian rhythms during consecutive night shifts and to study the effect of gender on the adjustment to night work.

Methods Twenty experienced shift workers, 9 men and 11 women, were studied under controlled laboratory conditions. After a night of habituation, the subjects worked one day shift and three night shifts. Rectal temperature was measured continuously during the study. Salivary melatonin and cortisol were assessed at 2-h intervals, and subjective sleepiness was checked every hour during the work shifts. Sleep was registered by the static-charge sensitive bed (SCSB) method after the workshifts.

Results Subjective sleepiness varied both between the work shifts and between the men and women. The subjects felt most alert during the day shift and were the sleepiest during the first night shift. Sleepiness decreased during the consecutive night shifts but did not reach the level of the day shift during the three nights. The sleepiness of the women decreased more than that of the men, the difference being significant during the second and third night shifts $(\mathrm{P}<0.05)$. The circadian rhythm of body temperature, salivary cortisol, and time in bed changed significantly $(P<0.05)$ between the workshifts, but no differences were found between the men and women in the circadian adjustment of the physiological variables to night work.

Conclusions The men felt sleepier than the women during the consecutive night shifts, although no physiological differences were found between the genders. However, since normal social and domestic factors were excluded, the findings cannot be considered as evidence of women's better adaptation to night work in everyday life.
\end{abstract}

Key terms laboratory study, rectal temperature, salivary cortisol, salivary melatonin, sex difference, sleep, subjective sleepiness.

Most nightshift workers have problems sleeping during the day (1) and during night shifts they experience severe sleepiness (2). The basic mechanism causing the sleep disturbances of night workers seems to be circadian. On the other hand, the sleep of shift workers is also greatly disturbed by environmental and domestic factors under natural conditions (3). Most studies on the effects of night work on sleep and circadian rhythms have been conducted under field conditions with many environmental factors disturbing sleep $(4,2)$. Experimental studies on the circadian adjustment process during consecutive night shifts are rare (5-10). The experimental studies are also contradictory as regards sleepiness; it has been shown to decrease $(11-13)$, to increase $(14,10)$, or to remain unchanged (15) during consecutive night shifts.

There are also great individual differences in the tolerance to shift work (16). Especially women have tradi- tionally been protected from night work. Surprisingly, we are not aware of any controlled experimental studies on the effects of gender on the circadian adjustment to night work. The circadian patterns of men and women are almost identical (17), but some indications of differences between the two in circadian rhythms $(18,19)$ and sleep structure $(20,21)$ have been detected. However, most of the data indicating differences in their responses to shift work are based on psychosocial studies (2224). In shift work, women have been shown to have more psychosomatic complaints and higher absenteeism from work than men. Furthermore, the prevalence of sleep disturbances and drowsiness at work has been reported to be higher among female shiftworkers $(25,23)$.

The present study was designed to define the exact adjustment of sleep-wakefulness and the circadian rhythms of body temperature, melatonin, and cortisol

1 Department of Physiology, Finnish Institute of Occupational Health, Vantaa, Finland.

2 Department of Physiology, Kuopio University, Kuopio, Finland.

Reprint requests to: Dr Mikko Härmä, Department of Physiofogy, Finnish Institute of Occupational Health, Laajaniityntic 1, FIN-01620 Vantaa, Finland. 
during consecutive night shifts. In addition, the objective was to compare the adjustment to night work between men and women under closely controlled laboratory conditions.

\section{Subjects and methods}

\section{Subjects}

Twenty experienced postal workers, 9 men (mean age 40.6 years) and 11 women (mean age 38.8 years), were studied (table 1). The main work task of the subjects was manual letter sorting. Six men and nine women v'ere three-shift workers, while three men and two women had two-shift work without night shifts at the time of the study. The shift work experience of the men was still somewhat longer than that of the women (table 1). There were no differences in the diurnal type scale $(26$, morningness-eveningness) between the subjects (table 1). According to a routine medical examination, all the subjects were healthy, and none were on continuous medication. Four men and three women said that they "snore loudly," but none had sleep apnea according to the measurements of the static-charge sensitive bed (SCSB), which included a continuous registration of respiration. The subjects were paid for their participation.

\section{Design}

Every subject stayed in the shiftwork laboratory for one week. After a night of habituation, the subjects worked one day shift and three consecutive night shifts. The shift work laboratory was equipped with facilities for controlled letter-sorting work, sound-proof sleeping chambers, and a separate room for leisure time. The windows were darkened from sunlight to 1500 during the day time, and the light intensity was always below $1000 \mathrm{~lx}$ in the laboratory.

During the day shift, the subjects worked between 0900 and 1600 and were allowed to have a 60-min lunch hour and a 30-min coffee break. After the work they had leisure time and were allowed to sleep between 2230 and 0630. During the night shift, the subjects worked from 2300 to 0600 and were allowed to take one 30-min break. After the night shift they slept between 0630 and 1430 and had leisure time before the next night shift. The work task of the subjects was letter sorting, mimicking that at their actual workplace; the work was self-paced. The subjects spent their leisure time watching television, reading, doing needlework, and such. The meal times during the week were kept regular, with moderate consumption of coffee. Napping, sauna, exercise, or alcohol was not allowed.

\section{Circadian rhythms}

Rectal temperature $\left(\mathrm{T}_{\mathrm{re}}\right)$ was measured continuously with recordings every third minute during the week with a thermistor probe (YSI 401, Yellow Spring Instruments, United States) that was inserted about $10 \mathrm{~cm}$ into the rectum. The $\mathrm{T}_{\mathrm{re}}$ was recorded with a desk-top computer (HP9122, Hewlett Packard, United States) via an analogue-digital (A/D) converter (HP3421A). To smooth the fluctuation of the $T_{r c}$, the mean temperature values for every $30 \mathrm{~min}$ were calculated from the raw data and the time of the $\mathrm{T}_{\mathrm{re}}$ minimum was estimated visually from the smoothed data.

Melatonin and cortisol were determined from samples of saliva, collected at 12-h intervals during the workshifts. Unstimulated saliva $(2.5 \mathrm{ml})$ was collected into polyethylene tubes and stored in a freezer $\left(-20^{\circ} \mathrm{C}\right)$. The melatonin concentration was determined after chloroform extraction using a modification (27) of radioimmunoassay, originally described by Miles et al (28). Cortisol was determined by direct radioimmunoassay, as described earlier (27).

\section{Sleep-wakefulness}

The time in bed and the autonomic sleep phases were registered using the SCSB method (29). From the SCSB, the ballistocardiogram, respiratory movements, and movements specific for postural changes can be registered simultaneously by selective filtering of the original signal. After A/D conversion, the frequencies of different movements were analyzed (BR11, Biorec, 30), and the sleep was classified into autonomic sleep phases (active, intermediate, and quiet sleep) in epochs of $3 \mathrm{~min}$. The time of falling asleep was estimated according to the appearance of the first phase of quiet sleep for $3 \mathrm{~min}$.

Subjective sleepiness was studied every hour during the workshifts with the Karolinska sleepiness scale (KSS) (31), which is a modification of the Stanford sleepiness scale. The Karolinska scale includes the following phases: extremely alert (score $=1)$, alert (score $=3$ ), neither

Table 1. Characteristics of the subjects.

\begin{tabular}{|c|c|c|c|c|c|c|c|c|c|c|}
\hline & \multicolumn{2}{|c|}{$\begin{array}{c}\text { Age } \\
\text { (years) }\end{array}$} & \multicolumn{2}{|c|}{$\begin{array}{l}\text { Body mass index } \\
\qquad\left(\mathrm{kg} \cdot \mathrm{m}^{-2}\right)\end{array}$} & \multicolumn{2}{|c|}{$\begin{array}{c}\text { Diurnal type } \\
\text { scale }^{a}\end{array}$} & \multicolumn{2}{|c|}{$\begin{array}{c}\text { Work experience } \\
\text { (years) }\end{array}$} & \multicolumn{2}{|c|}{$\begin{array}{c}\text { Shift work } \\
\text { experience (years) }\end{array}$} \\
\hline & Mean & SD & Mean & SD & Mean & SD & Mean & SD & Mean & SD \\
\hline $\operatorname{Men}(N=9)$ & 40.6 & 13.2 & 26.3 & 3.6 & 2.6 & 1.0 & 21.1 & 13.3 & 13.6 & 13.2 \\
\hline Women $(N=11)$ & 38.8 & 16.6 & 25.4 & 5.1 & 2.6 & 0.5 & 14.7 & 12.8 & 3.8 & 3.8 \\
\hline
\end{tabular}

a See reference 26 . 
alert nor sleepy (score $=5$ ), sleepy but no difficulty in remaining awake (score $=7$ ), extremely sleepy, fighting sleep $($ score $=9)$.

\section{Statistics}

The effect of gender, day (day shift and three night shifts), time of day (0900-1500 and 2400-0600), and their interactions were studied by repeated-measures analyses of variance. The assumption for probabilities provided by ordinary F-tests to be correct was tested by a sphericity test (32). If the sphericity test was significant, an adjusted F-test (33) was used. In cases in which the P-value of the sphericity test was lower than 0.0001 , a multivariate analysis of variance was used. Pairwise comparisons were done when the overall F-ratio was significant.

\section{Results}

Results of the analysis of variance of all the studied variables are presented in table 2 . The $T_{\text {re }}$ minimum (figure 1) varied between the days, reaching its minimum between 0400 and 0500 after the day shift and between 0700 and 0900 after the night shifts. The delay of the mean $(\mathrm{N}=20) \mathrm{T}_{\mathrm{re}}$ minimum averaged 3.3 (SD 1.8) $\mathrm{h}$ during the first night shift and a further 0.5 (SD 2.0) $\mathrm{h}$ during the following night shifts.

According to the analysis of variance with repeated measures, the interaction of gender and day was not significant (table 2). However, there was a mean difference of 1.2 (SD 2.1) h in the $\mathrm{T}_{\mathrm{re}}$ minimum between the men and women after the third night shift, the men showing slightly more (not significant) adjustment than the women.

Salivary melatonin (figure 2) secretion diminished during the first hours of the day shift, but increased towards the early morning hours of the night shifts, the time effect being significant (table 2). There was no day or gender effect nor any significant interactions with salivary melatonin secretion.

The salivary cortisol (figure 3) secretion levels were altered between the shifts and showed a significant interaction between day and the time of day (table 2). The mean cortisol level was the highest in the beginning of the day shift, decreasing towards the end of the shift. During the consecutive night shifts the cortisol showed an increasing trend but a lowering level. There was no difference in cortisol secretion between the men and the women.

According to the SCSB recordings (figure 4), there were only small nonsignificant differences between the shifts in the time of falling asleep and in the length of autonomic sleep phases, but the time in bed varied clearly between the days (table 2). There was no significant
Table 2. Results of the analysis of variance with repeated measures ( $\varepsilon=$ Huynh-Feldt epsilon) or multivariate analysis of variance (Manova): effects of gender, day, and time and their interactions. (NS $=$ not significant $)$

\begin{tabular}{|c|c|c|c|c|}
\hline Effect & $\begin{array}{l}\text { Degrees } \\
\text { of freedom }\end{array}$ & F-value & $P$-value & $\varepsilon$ \\
\hline \multicolumn{5}{|l|}{$\begin{array}{l}\text { Minimum rectal } \\
\text { temperature }\end{array}$} \\
\hline $\begin{array}{l}\text { Gender } \\
\text { Day } \\
\text { Gender - day }\end{array}$ & $\begin{array}{l}1,18 \\
3,54 \\
3,54\end{array}$ & $\begin{array}{r}3.21 \\
37.67 \\
0.85\end{array}$ & $\begin{array}{l}\text { NS } \\
0.0001 \\
\text { NS }\end{array}$ & \\
\hline \multicolumn{5}{|l|}{ Melatonin } \\
\hline $\begin{array}{l}\text { Gender } \\
\text { Day } \\
\text { Gender · day } \\
\text { Time } \\
\text { Gender · time } \\
\text { Day t time } \\
\text { Gender - day - time }\end{array}$ & $\begin{array}{l}1,18 \\
3,54 \\
3,54 \\
4,15 \\
4,15 \\
7,12 \\
7,12\end{array}$ & $\begin{array}{l}0.94 \\
1.90 \\
1.05 \\
3.14 \\
0.44 \\
1.53 \\
0.65\end{array}$ & $\begin{array}{l}\text { NS } \\
\text { NS } \\
\text { NS } \\
0.046 \\
\text { NS } \\
\text { NS } \\
\text { NS }\end{array}$ & $\begin{array}{l}=0.71 \\
=0.71 \\
\text { Manova } \\
\text { Manova } \\
\text { Manova } \\
\text { Manova }\end{array}$ \\
\hline \multicolumn{5}{|l|}{ Cortisol } \\
\hline $\begin{array}{l}\text { Gender } \\
\text { Day } \\
\text { Gender - day } \\
\text { Time } \\
\text { Gender · time } \\
\text { Day - time } \\
\text { Gender - day - time }\end{array}$ & $\begin{array}{l}1,18 \\
3,16 \\
3,16 \\
4,72 \\
4,72 \\
12,7 \\
12,7\end{array}$ & $\begin{array}{r}0.01 \\
30.61 \\
1.47 \\
1.44 \\
0.39 \\
3.87 \\
2.82\end{array}$ & $\begin{array}{l}\text { NS } \\
0.0001 \\
\text { NS } \\
\text { NS } \\
\text { NS } \\
0.04 \\
\text { NS }\end{array}$ & $\begin{array}{l}\text { Manova } \\
\text { Manova } \\
=0.83 \\
=0.83 \\
\text { Manova } \\
\text { Manova }\end{array}$ \\
\hline \multicolumn{5}{|l|}{ Active sleep } \\
\hline $\begin{array}{l}\text { Gender } \\
\text { Day } \\
\text { Gender · day }\end{array}$ & $\begin{array}{l}1,18 \\
3,54 \\
3,54\end{array}$ & $\begin{array}{l}1.44 \\
0.61 \\
0.21\end{array}$ & $\begin{array}{l}\text { NS } \\
\text { NS } \\
\text { NS }\end{array}$ & \\
\hline \multicolumn{5}{|l|}{ Intermediate sleep } \\
\hline $\begin{array}{l}\text { Gender } \\
\text { Day } \\
\text { Gender · day }\end{array}$ & $\begin{array}{l}1,18 \\
3,54 \\
3,54\end{array}$ & $\begin{array}{l}0.35 \\
1.72 \\
0.93\end{array}$ & $\begin{array}{l}\text { NS } \\
\text { NS } \\
\text { NS }\end{array}$ & $\begin{array}{l}=0.79 \\
=0.79\end{array}$ \\
\hline \multicolumn{5}{|l|}{ Quiet sleep } \\
\hline $\begin{array}{l}\text { Gender } \\
\text { Day } \\
\text { Gender - day }\end{array}$ & $\begin{array}{l}1,18 \\
3,54 \\
3,54\end{array}$ & $\begin{array}{l}0.12 \\
2.21 \\
1.00\end{array}$ & $\begin{array}{l}\text { NS } \\
\text { NS } \\
\text { NS }\end{array}$ & \\
\hline \multicolumn{5}{|l|}{ Quiet sleep latency } \\
\hline $\begin{array}{l}\text { Gender } \\
\text { Day } \\
\text { Gender - day }\end{array}$ & $\begin{array}{l}1,18 \\
3,54 \\
3,54\end{array}$ & $\begin{array}{l}0.10 \\
2.00 \\
0.36\end{array}$ & $\begin{array}{l}\text { NS } \\
\text { NS } \\
\text { NS }\end{array}$ & $\begin{array}{l}=0.79 \\
=0.79\end{array}$ \\
\hline \multicolumn{5}{|l|}{ Time in bed } \\
\hline $\begin{array}{l}\text { Gender } \\
\text { Day } \\
\text { Gender - day }\end{array}$ & $\begin{array}{l}1,18 \\
3,54 \\
3,54\end{array}$ & $\begin{array}{l}0.03 \\
0.09 \\
0.23\end{array}$ & $\begin{array}{l}\text { NS } \\
0.009 \\
N S\end{array}$ & \\
\hline \multicolumn{5}{|l|}{ Subjective sleepiness } \\
\hline $\begin{array}{l}\text { Gender } \\
\text { Day } \\
\text { Gender - day } \\
\text { Time } \\
\text { Gender - time } \\
\text { Day t time } \\
\text { Gender day - time }\end{array}$ & $\begin{array}{l}1,18 \\
3,54 \\
3,54 \\
6,108 \\
7,12 \\
1,18 \\
1,18\end{array}$ & $\begin{array}{r}1.58 \\
9.10 \\
4.01 \\
34.09 \\
0.93 \\
6.75 \\
0.38\end{array}$ & $\begin{array}{l}\text { NS } \\
0.0003 \\
0.02 \\
0.0001 \\
\text { NS } \\
\text { NS } \\
\text { NS }\end{array}$ & $\begin{array}{l}=0.76 \\
=0.76 \\
=0.70 \\
=0.70 \\
\text { Manova } \\
\text { Manova }\end{array}$ \\
\hline
\end{tabular}

difference in any sleep variable between the men and the women.

The subjective sleepiness (KSS, figure 5) varied between the workshifts (effect of day, table 2) with significant differences ( $\mathrm{t}$-test, $\mathrm{P}<0.05$ ) between all the shifts. The subjects felt the most alert during the day shift and were the sleepiest during the first night shift. The mean sleepiness decreased during the consecutive night shifts, but it did not reach the level of the day shift during the 


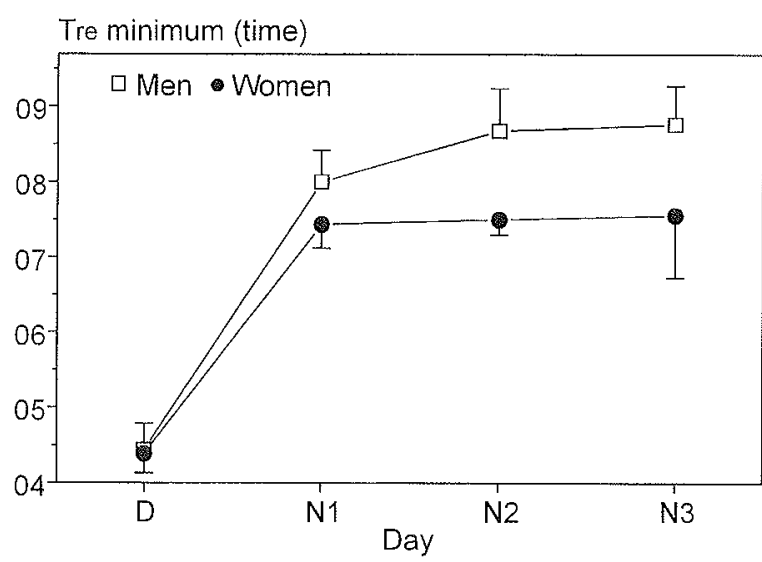

Figure 1. Time of the mean and the standard error of the mean of the rectal temperature $\left(T_{r e}\right)$ minimum of the men and women during the days of the day shift (D) and three consecutive night shifts (N1-N3).

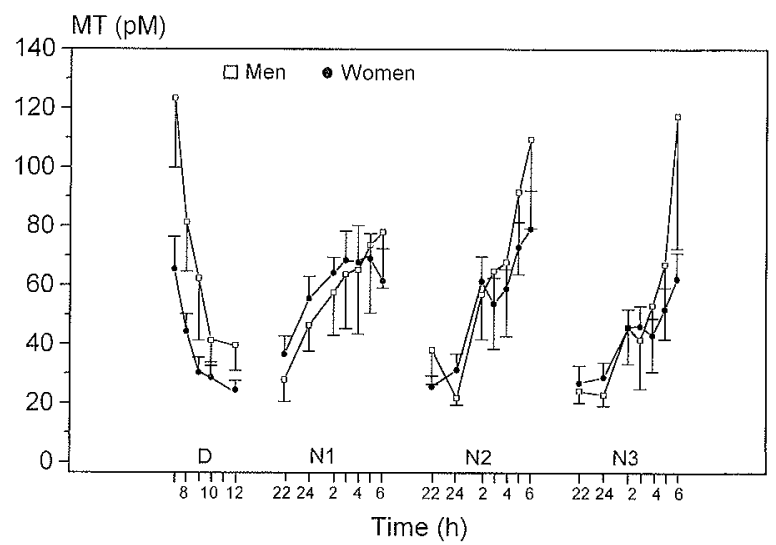

Figure 2. Mean and the standard error of the mean for the salivary melatonin (MT) excretion of the men and women during the day shift (D) and three consecutive night shifts (N1-N3).

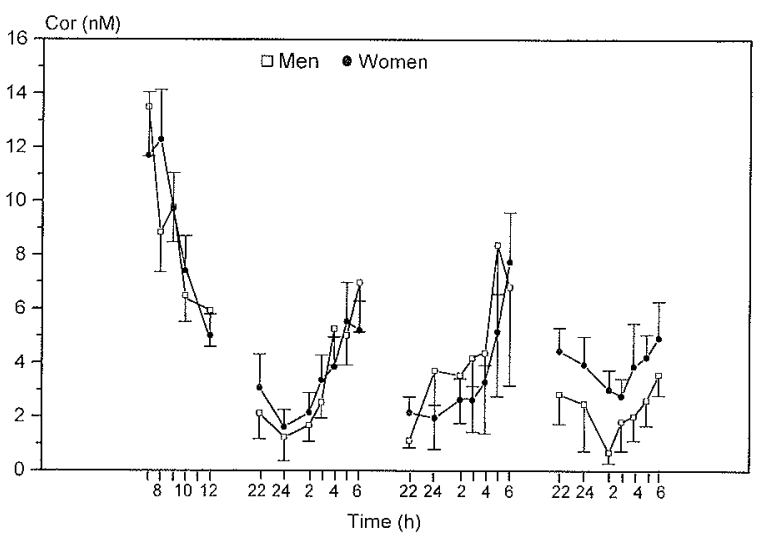

Figure 3. Mean and the standard error of the mean for the salivary cortisol (Cor) excretion of the men and women during the day shift (D) and three consecutive night shifts (N1-N3).

three nights. In relation to the time of day, sleepiness did not change notably during the day shift, but it increased considerably towards the end of the night shifts (effect of

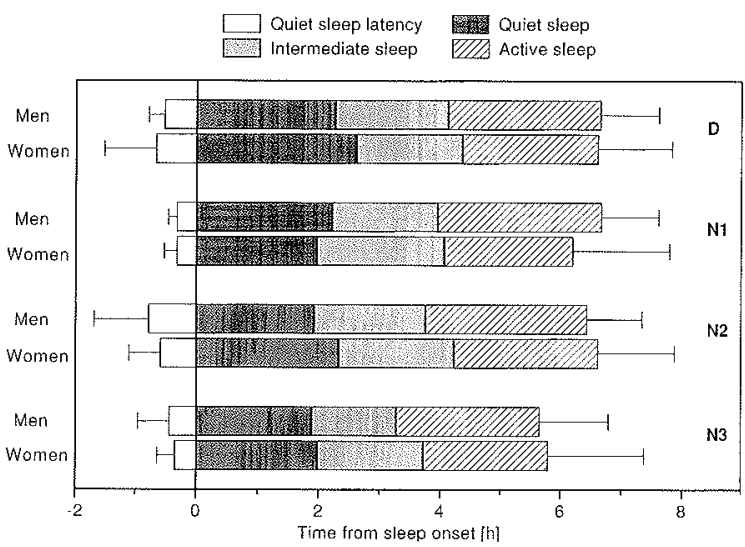

Figure 4. Mean and the standard error of the mean for the autonomic sleep phases of the men and women during the day shift (D) and three consecutive night shifts (N1-N3).

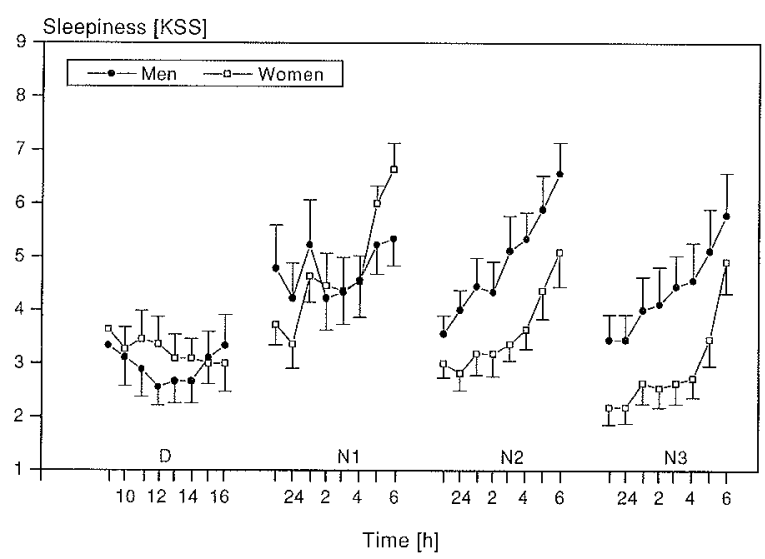

Figure 5. Mean and standard error of the mean for subjective sleepiness among the men and women during the day shift (D) and three consecutive night shifts (N1-N3). (KSS = Karolinska sleepiness scale)

time, table 2). Subjective sleepiness also differed between the men and women in various shifts (interaction effect of gender and day, table 2). During the day shift there was no difference in perceived sleepiness between the men and the women, but in the course of the night shifts the women felt less sleepy than the men, especially during the second and the third night shift, the difference being significant ( $t$-test, $\mathrm{P}<0.05$ ).

\section{Discussion}

The men felt sleepier than the women during consecutive night shifts, although no physiological differences were found in the circadian rhythms of body temperature, salivary melatonin, and cortisol or in sleep between the genders. In fact, there was a nonsignificant trend for men adjusting faster than women. This finding indicates that the women's increasing alertness during night shifts can- 
not be due to differences in circadian adjustment. Our results are in accordance with those of the study of Akerstedt \& Fröberg (17) showing that the circadian rhythms of the two genders were almost identical, and the only difference was that the men were characterized by increasing trends in ratings of fatigue and stress and the women were not during a $72-\mathrm{h}$ sleep deprivation experiment. These results thus indicate that there is no clear physiological difference between men and women which would indicate that women adjust to night work worse than men. However, the difference in sleepiness cannot be considered evidence of women's better adjustment to night work in everyday life, because normal social and domestic factors were excluded from the laboratory study. Although there appear to be no great sex-related differences in the adaptation to night work, women seem to tolerate night work less than men because of the gender-related extra work load due to household duties and child care (22). In fact, the usually greater family responsibilities of women $(22,23)$ probably cancel out the potential benefit of circadian adjustment.

The question of whether shift work should be organized by rapidly or slowly rotating night shifts is still one of the major issues in shiftwork research (34). The main argument favoring slowly rotating shift work is the claim that sleepiness decreases during consecutive night shifts because of the circadian adjustment process contrary to, for example, single night shifts in very rapid rotating systems. In our study, subjective sleepiness decreased gradually from the first night shift to the third but did not reach the earlier level of the day shift. The recovery of sleepiness during the consecutive night shifts shows that there was no cumulative sleep deficit due to night work. We want to point out, however, that this was a laboratory study with a good sleeping environment, and the same kind of recovery can be achieved under field conditions only if subjects can sleep sufficiently. The present results, which show improvement in alertness during consecutive night shifts, still support the hypothesis that slowly rotating shift schedules can be better than rapidly rotating schedules when good sleeping conditions are available.

The reason for the increased level of sleepiness during the first night shift seems to be homeostatic. At the end of the first night shift the subjects had been awake for $24 \mathrm{~h}$, while in later night shifts the preceding awake period was only $16 \mathrm{~h}$. The considerable reduction of sleepiness during the consecutive night shifts was presumably also due to homeostatic rather than circadian mechanisms, since the phase delay of the $\mathrm{T}_{\mathrm{re}}$ minimum was minimal at the same time $(0.5 \mathrm{~h}$ per day). On the average, however, the subjects did not perceive severe sleepiness during the night shifts, and sleepiness varied within a rather normal range, in other words "sleepy but no difficulty in remaining awake" (31). In spite of being monotonous, letter sorting is self-paced and apparently motional enough to prevent dozing off at work.

Sleep length and latency were shortened after the night shifts, as expected $(35,36)$. An unexpected finding was the shortening of the quiet sleep phases in connection with day sleep. In the validation study of the SCSB method (37) we found that the phases of quiet sleep consist of mostly delta sleep (69\%). In earlier encephalographic studies, slow wave sleep (stage 34 ) increased (35) or did not change (36) after the night shifts due to the sleep deprivation.

The timing of the $\mathrm{T}_{\mathrm{re}}$ minimum did not change significantly during the consecutive night shifts, but the deviation of the $T_{r e}$ minimum increased, being greatest after the third night shift. The results suggest that the phase delay of body temperature rhythm was only partial during consecutive night shifts, as suggested earlier (4). The delay of the $\mathrm{T}_{\mathrm{re}}$ minimum was the most pronounced when the subjects changed from the day to the night shift, probably due to "masking" effects $(38,39)$. The adjustment from the day to the first night shift was thus "overestimated" (38). It was, however, possible to study the impact of gender on the circadian rhythm of $\mathrm{T}_{\mathrm{rc}}$ since the masking factors of sleep, activity, and work were similar (same starting time) during the consecutive night shifts. Furthermore, the $\mathrm{T}_{\mathrm{re}}$ minimum always occurred after sleep onset, reducing potential variation due to the different masking effects of sleep.

An interesting finding was that the mean salivary melatonin secretion profiles did not change during the consecutive night shifts, mainly because of the great interindividual alterations. Our results thus support some earlier findings that night shift workers have great variability in the timing of melatonin secretion (40) and may not actually show remarkable changes in melatonin rhythm during night work $(41,42)$. The secretion patterns of salivary cortisol, unlike the melatonin profiles, still changed, a phase delay thus being suggested for the consecutive night shifts.

In conclusion, the adjustment of circadian rhythms in the course of the night shifts was slow and only partial. Subjective sleepiness still decreased in the course of the night shifts, and the men felt sleepier than the women during the consecutive night shifts, although no physiological explanation was found.

\section{References}

1. Waterhouse JM, Folkard S, Minors DS. Shiftwork, health and safety: an overview of the scientific literature 1978-1990. London: Health and Safety Executive, 1992.

2. Akerstedt T. Psychological and psychophysiological effects of shift work. Scand J Work Environ Health 1990;16:67-73.

3. Scott AJ, LaDou J. Health and safety in shift workers. In: 
Dickerson OB, Horvath EP, editors. Occupational medicine. St Louis (MO): Mosby-Year Book Inc, 1994;960—86.

4. Åkerstedt T. Adjustment of physiological circadian rhythms and sleep-wake cycle to shiftwork. In: Folkard S, Monk TH, editors. Hours of work. Chichester (England): John Wiley and Sons Ltd, 1985;185-97.

5. Colquhoun WP, Blake MJF, Edwards RS. Experimental studies of shift-work II: stabilized 8-hour shift systems. Ergonomics 1968;11:527-46.

6. Knauth P, Rutenfranz J. Experimental shift work studies of permanent night, and rapidly rotating, shift systems I: circadian thythm of body temperature and re-entrainment at shift change. Int Arch Occup Environ Health 1976;37:125-37.

7. Knauth P, Rutenfranz J, Herrmann G, Poeppl SJ. Re-entrainment of body temperature in experimental shift-work studies. Ergonomics 1978;21:775-83.

8. Moog R. Optimization of shift work: physiological contributions. Ergonomics 1987;30:1249-59.

9. Dahlgren K. Adjustment of circadian rhythms and EEG sleep functions to day and night sleep among permanent night workers and rotating shift workers. Psychophysiology 1981;18: $381-91$.

10. Dahlgren K. Temporal patterns in psychophysiological activation in rotating shift workers: a follow-up field study one year after an increase in nighttime work. Scand J Work Environ Health 1981;7:131-40.

11. Wilkinson R, Allison S, Feeney M, Kaminska Z. Alertness of night nurses; two shift systems compared. Ergonomics 1989; 32:282-92.

12. Fröberg JE, Karlsson CG, Levi L. Shift work: a study of catecholamine excretion, self-ratings and attitudes. Stud Laboris Salutis 1972;11:10-20.

13. Folkard S, Monk TH, Lobban MC. Short and long term adjustment of circadian rhythms in "permanent" night nurses. Ergonomics 1978;21:785-99.

14. Chaumont AJ, Laporte A, Nicolai A, Reinberg A. Adjustment of shift workers to a weekly rotation. Chronobiologia 1979;6 suppl: 27-36.

15. Minors DS, Waterouse JM. Circadian rhythms in deep body temperature, urinary excretion and alertness in nurses on night work. Ergonomics 1985;28:1523 - 30

16. Härmä M. Individual differences in tolerance to shiftwork: a review. Ergonomics 1993;36:101 -9.9.

17. Åkerstedt T, Fröberg JE. Psychophysiological circadian rhythms in women during $72 \mathrm{~h}$ of sleep deprivation. Waking Sleeping 1977;1:387-94.

18. Campbell SS, Gillin JC, Kripke DF, Erikson P, Clopton P. Gender differences in the circadian temperature rhythms of elderly subjects: relationships to sleep quality. Sleep 1989;12: $529-36$.

19. Adan A. Axillary temperature measure as a biological thythm marker: a diurnal study. Med Sci Res 1991;19:735-6.

20. Dijk DJ, Beersma DGM, Bloem GM. Sex differences in the sleep EEG of young adults: visual scoring and spectral analysis. Sleep 1989;12:500-5.

21. Rediehs MH, Reis JS, Creason NS. Sleep in old age: focus on gender differences. Sleep 1990;13:410-24.

22. Dirkx J, Recent reset on night work for women: a review. In: Singleton WT, Dirkx J, editors. Ergonomics, health and safety: perspectives for the nineties. Leuven: Leuven University Press, 1991;59-75.
23. Oginska H, Pokorski J, Oginski A. Gender, ageing, and shiftwork intolerance. Ergonomics 1993;36:161-8.

24. Kandolin I. Burnout of female and male nurses in shiftwork Ergonomics 1993;36:141-7.

25. Monk TH, Folkard S. Individual differences in shiftwork adjustment. In: Folkard S, Monk TH, editors. Hours of work. Chichester (England): John Wiley and Sons Ltd, 1985;22737.

26. Torsvall L, Åkerstedt T. A diurnal type scale: construction, consistency and validation in shift work. Scand J Work Environ Health 1980;6:283-90.

27. Härmä M, Laitinen J, Partinen $M$, Suvanto $S$. The effect of four-day round trip flights over 10 time zones on the circadian variation of salivary melatonin and cortisol in airline flight attendants. Ergonomics 1994:37:1479—-89.

28. Miles A, Philbrick D, Tidmarch SF, Shaw DM. Direct radioimmunoassay of melatonin in saliva. Clin Chem 1985;3: $1412-3$.

29. Alihanka J. Sleep movements and associated autonomic nervous activities in young male adults [dissertation]. Acta Physiol Scand 1982;suppl 511:1-85.

30. Alihanka J. Basic principles for analysing and scoring Biobatt (SCSB) recording. Turku (Finland): University of Turku, 1985.

31. Åkerstedt T, Gillberg M. Subjective and objective sleepiness in the active individual. Int J Neurosci 1990;52:29 —37.

32. Anderson TW. An introduction to multivariate statistical analysis. New York (NY): John Wiley \& Sons Inc, 1958.

33. Huynh H, Feldt LS. Estimation of the Box correction for degrees of freedom from data in the randomized block and split plot designs. J Educ Stat 1976;1:69-82.

34. Wilkinson RT. How fast should the night shift rotate? Ergonomics 1992;35:1425-46.

35. Kiesswetter E. A polysomnographic study of morning and afternoon sleep quality during simulated night shift work. Ergonomies 1993;36:265-72.

36. Åkerstedt T, Kecklund G, Knutsson A. Manifest sleepiness and the spectral content of the EEG during shift work. Sleep 1991;14:221-5.

37. Pulli K, Härmä M, Hasan J, Värri A, Loula P. The relationship between delta activity and autonomic activity as measured by SCSB during sleep. J Sleep Res 1994;3:106-10.

38. Minors DS, Waterhouse JM. Separating the endogenous and exogenous components of the circadian rhythm of body temperature during night work using some 'purification' models. Ergonomics 1993:36:497-507.

39. Härmä M, Waterhouse J, Minors D, Knauth P. Effect of masking on circadian adjustment and interindividual differences on rapidly rotating shift schedule. Scand J Work Environ Health 1994;20:55-61.

40. Sack RL, Blood ML, Lewy AJ. Melatonin rhythms in night shift workers. Sleep 1992;15:434-41.

41. Touitou Y, Motohashi Y, Reinberg A, Touitou C, Bourdeleau $P$, Bogdan $P$, et al. Effect of shift work on the night-time secretory patterns of melatonin, prolactin, cortisol and testosterone. Eur J Appl Physiol 1990;60:288- -92.

42. Cagnacci A, Elliot IA, Yen SSC. Melatonin; a major regulator of the circadian rhythm of core temperature in humans. $J$ Clin Endocrinol Metab 1992;75:447—52.

Received for publication: 18 April 1995 